The National Audit Office came to this unit for the data and despite being given graphs and bar charts requested the raw data as well. The published graph of male trends in mortality was prepared here. The bar chart of comparative mortality, however, which was reproduced in the $B M F$ and by the national media, originated within the National Audit Office. It makes out Sweden to have the highest coronary heart disease mortality of the developed economies. Unfortunately, my exhortation not to use crude all ages rates cannot have been passed on to whoever prepared the graph, which was not checked with me.

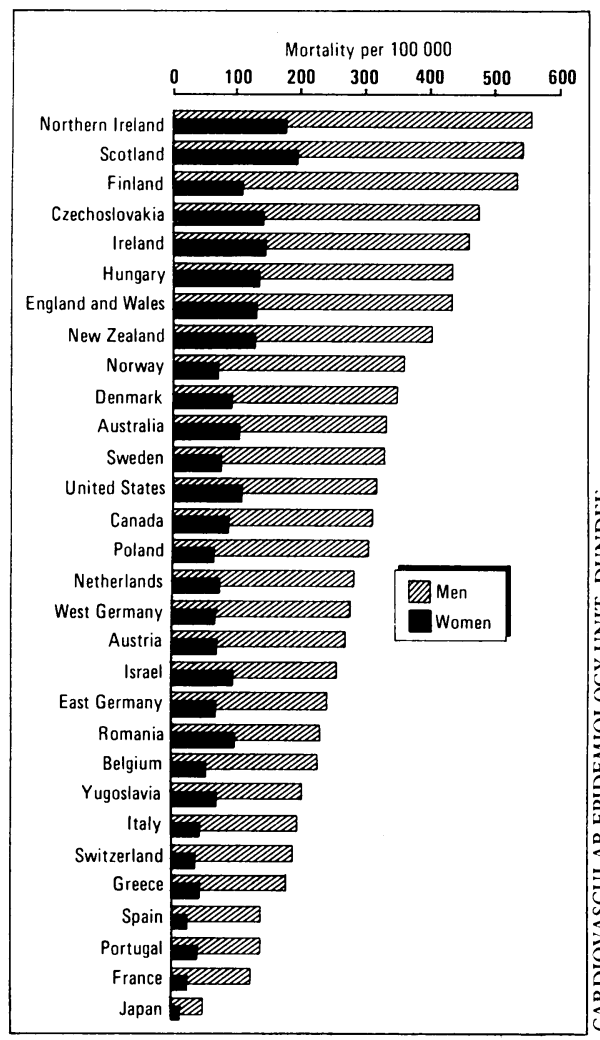

Coronary heart disease mortality in men and women aged 40-69 (age standardised)

In Sweden there is a low age specific mortality, a high life expectancy, and a large proportion of elderly people who die at an advanced age from coronary heart disease. Hence the high crude, all ages rate and a bar chart for coronary mortality that shows little correlation with the age specific or age standardised data and reflects more on the age structure of the nations concerned.

The National Audit Office is now submitting a different version of this graph to the House of Commons. The bar chart appearing here, which was prepared in the unit and has been made available to others, shows the league table for 1985 rates (or the nearest available year), age standardised for the age group 40-69; Sweden is well down the list.

In defence of the National Audit Office I should say that the age standardised results reinforce the main message of its report more than the original version of this graph. It is a paradox that this unorthodox graph seems to have achieved a much wider circulation than the epidemiologically correct material prepared from this unit (perhaps we ought to have trendy computer graphics) and that no one seems to have challenged it before, although many must have been puzzled.

HUGH TUNSTALL-PEDOE

Cardiovascular Epidemiology Unit.

Ninewells Hospital and Medical School,

Dundee DDI 9 SY

1 Anonymous. Small change in heart disease mortality: still hundreds of thousands dead. Br Med 7 1989;298:552. (4 March.)

\section{Prevention of atherosclerotic complications with ketanserin}

SIR, - The paper by the Prevention of Atherosclerotic Complications with Ketanserin Tria Group must seem to embody a strange approach to cardiologists interested in the possibility that this drug might prevent myocardial infarction.' The fact that patients with intermittent claudication were selected for such a trial removes any likelihood that the results are relevant to coronary heart disease.

For such relevance we think that patients with critical coronary artery stenoses shown by coronary angiography must be selected. We have taken this approach and have thus far followed up 30 patients treated with aspirin and 32 matched patients treated with ketanserin until they underwent coronary artery bypass grafting or angioplasty. During this period none of the patients treated with ketanserin have had any cardiac ischaemic episodes; one patient died of carcinoma of the oesophagus. Six patients in the control group, three of whom died, had myocardial infarction. These results constitute appreciable protection by ketanserin and suggest that the hypothesis that serotonin is important in the mechanism of coronary arterial occlusion is still worth further investigation. We suggest that the hypothesis could be tested in such high risk coronary stenosis patients with about a tenth of the number of patients recruited into the ketanserin trial.

The main precautions required in conducting further trials with ketanserin are not absolute exclusion of potassium losing diuretic and antiarrhythmic comedication as implied. Patients should have a potassium retaining diuretic added to their regimen and should be withdrawn from the trial if the absolute QT interval (not the corrected QT interval) exceeds $500 \mathrm{~ms}$ (such prolongation predisposes to torsade de pointes arrhythmia) or the serum potassium concentration falls below $3.5 \mathrm{mmol} / \mathrm{l}$ (not 3.0 ). With these criteria no arrhythmic problems need be expected, according to our experience; indeed, in one patient frequent episodes of monofocal ventricular tachycardia have been controlled by the class III antiarrhythmic action of ketanserin.

Department of Medicine,

MARK I M NOBLE

Charing Cross and Westminster Medical School,

Westminster Hospital

London SW IP 2AP

Department of Medicine,

ANGELA J DRAKE HOLLAND

St George's Hospital Medical School,

London SW $170 \mathrm{RE}$

Prevention of Atherosclerotic Complications with Ketanserin Trial Group. Prevention of atherosclerotic complications: controlled trial of ketanserin. $\mathrm{Br}$ Med $\mathcal{J}$ 1989;298:424-30. (18 February.)

SIR, - The Prevention of Atherosclerotic Complications with Ketanserin Trial Group showed an excess of deaths in patients receiving ketanserin and potassium losing diuretics.' The group suggested that this may be attributed to exacerbation of hypokalaemia induced ventricular arrhythmias by the repolarisation prolonging effect of ketanserin. In the light of this we summarise the results of our study of the effects of ketanserin on ventricular ectopic activity.

Twenty patients with more than 15 ventricular ectopic beats per hour (but no ventricular tachycardia) were studied in a double blind crossover comparison of ketanserin $40 \mathrm{mg}$ twice daily and placebo, each for one week. Assessment was by 48 hour electrocardiograms, and analysis was by standard crossover techniques. Our protocol initially permitted any diuretic provided that the serum potassium concentration was normal, but when the recommendations of the Prevention of Atherosclerotic Complications with Ketanserin ethical and safety committee became known this was changed to permit only potassium sparing diuretics. Antiarrhythmic drugs were not permitted.

The mean serum potassium concentration in our study group was normal and identical $(4.4 \mathrm{mmol} / \mathrm{l})$ with both treatments. In common with the group's investigators and other workers we found that ketanserin significantly prolonged the corrected QT interval by a mean of $20 \mathrm{~ms}(\mathrm{p}<0.01)$. In our normokalaemic patients, however, this was associated with a reduction rather than an increase in ventricular ectopic activity. The mean number of hours in which ventricular couplets were seen was significantly lower with ketanserin $(6.5 v 8.8$ hours, $\mathrm{p}<0.01$, and a total ventricular activity score derived from the Lown classification was also significantly improved. Ketanserin was also associated with a lower mean total number of ventricular ectopic beats ( $384 v 428$ beats/hour) and with fewer hours in which ventricular bigeminy was seen ( $9.2 v 11.6$ hours), but neither of these comparisons reached significance.

We therefore suggest that in normokalaemic patients ketanserin suppresses rather than exacerbates ventricular ectopic activity.

IAN DEWS

CHRISTINE E MARKS MALCOLM VANDENBURG JOHN STEPHENS

Department of Cardiology

Oldchurch Hospital

Romford,

Essex RM7 0BE

1 Prevention of Atherosclerotic Complications with Ketanserin Trial Group. Prevention of atherosclerotic complications: controlled trial of ketanserin. Br Med $\mathcal{J}$ 1989;298:424-30. (18 February.)

\section{Ribavirin and acute bronchiolitis in infancy}

SIR, - Dr M Everard and colleagues' results with the small particle aerosol generator' differ from those of Dr D Cameron and colleagues, who reported large mass median diameters of ribavirin aerosol when administered by a small particle aerosol generator- $2 .{ }^{2}$ Our studies may throw some light on the discrepancy.

We measured particle size at the nebuliser orifice using compressed air flow rates of 6,12 , and $15 \mathrm{l} /$ minute. The measurements were made with a Malvern 2600 HSD laser particle sizer. Preliminary results showed wide deviations from the mean particle size distribution of $1 \cdot 3 \mu \mathrm{m}$ specified by the manufacturers (Viratek). ${ }^{3+}$ The reasons for these deviations were sought, and further measurements were made over a range of working pressures. The results showed little improvement.

Mean mass median diameter of particles generated by three aerosol generators at different flow rates

\begin{tabular}{lcccc}
\hline $\begin{array}{l}\text { Flow } \\
\text { rate } \\
(1 / \mathrm{min})\end{array}$ & $\begin{array}{c}\text { Mass median } \\
\text { diameter } \\
(\mu \mathrm{m})\end{array}$ & $\begin{array}{c}\text { Standard } \\
\text { deviation }\end{array}$ & $\begin{array}{c}\text { Standard } \\
\text { error of } \\
\text { mean }\end{array}$ & $\begin{array}{c}\text { Standard } \\
\text { deviation of } \\
\text { manufacturer's } \\
\text { specification }\end{array}$ \\
\hline 6 & 1.43 & 0.21 & $0 \cdot 12$ & 0.09 \\
12 & 1.83 & 0.12 & 0.07 & 0.37 \\
15 & 1.53 & 0.06 & 0.03 & 0.16 \\
\hline
\end{tabular}

On further investigation we noticed that most of the aerosol was not being drawn sufficiently through the laser beam. After realignment further measurements were taken from the three small particle aerosol generators at 6,12 , and $15 \mathrm{l} /$ minute. The results are shown in the table. 
They suggest that considerable care should be exercised during such measurements to ensure correct interpretation of particle size distribution.

PAUL A WHITE NUALA DUNNE

Departments of Biomedical Engineering and Anaesthetics, Brompton Hospital

London SW3 6HP

1 Everard $\mathrm{M}$, Milner AD, (lark A. Ribavirin and acute bronchiolitis in infancy. Br. Med f 1989:298:323. + February. (Cameron D, Clay M. Silverman .11. Ribavirin and acute bromchiclitis in infancs. Br.Med 7 1988:298:1+72. 3 December

3 McClung HV, Knight V, Gilbert BE, Wilson SZ, Quarls JM Ribavirin acrosol treatment in intluenza irus infection. 71 . 1983:249:2671-4.

+ Young HW, Dominik JW, Walker JS, et al. Continuous aerosol therapy using a modified Collison nebuliser. $f$ Clin. Microhiol

5 Britannia Pharmaceuticals. Britannia Pharmaceuticals small purticle acrosol generator model spag-2. Instructions for use. Redhill: Britannia Pharmaceuticals.

\section{Malignant fibrous histiocytoma}

SIR, - We reply to the correspondence ${ }^{12}$ about our article on malignant fibrous histiocytoma complicating chronic venous ulceration.

Dr Tina Green is incorrect in stating that the malignant fibrous histiocytoma reported by Routh et al arose as a complication of chronic venous ulceration. In this report they describe a tumour arising in an ulcer of traumatic origin overlying the site of a poorly aligned comminuted fracture of the tibia. The difference between these types of ulcer is important for two reasons. Firstly, traumatic ulcers of the sort reported by Routh et al are rare, whereas chronic venous ulceration is seen daily by medical practitioners in a wide range of disciplines. Secondly, trauma is in itself a factor that predisposes to malignant fibrous histiocytoma.

We can reassure Drs Patrick Sarsfield and Thomas J Clarke that staining for the $\$ 100$ antigen gave negative results in all three of the tumours we reported.

We initially submitted this report with a review of published work and histology. The format of a short report, with which we were asked to comply, allowed inclusion of only the most essential information.

J BERTH-JONES A FLETCHER

Leicester Royal Infirmary

Leicester LE1 5WW

1 Green $Г$. Maligant fibrous histiocitoma. Br Med f 1989;298: 601. (4 March.)

2 Sarsfield P, Clarke TJ. Malignant fibrous histiocytoma. Br.Med $\mathrm{J}$ 1989;298:601. (4 March.

3 Berth-Jones J, Graham-Brown RAC, Fletcher A, Henderson HP, Barrie WW. Malignant fibrous histiocytoma: a new complication of chronic venous ulceration. Br.Med f 1989;298: 230-1. (28 January.)

4 Kempson RL, Kyriakos M. Fibroxanthosarcoma of the soft tissues. A twpe of malignant fibrous histiocytoma. Cancer 1972;29:961.

\section{Smoking habits and passive smoking}

SIR, - Your review of my book Misclassification of Smoking Habits and Passive Smoking incorrectly quotes me as stating that there is no risk in passive smoking. ${ }^{1}$ In fact, I presented detailed evidence to support my view that "it seems far more plausible to conclude that the epidemiologically observed association between passive smoking and lung cancer arose from bias due to misclassification of a proportion of smokers as non-smokers than to believe that it arose from any direct effect of passive exposure to low concentrations of environmental tobacco smoke."

Your review also stated incorrectly that I am a member of the Tobacco Research Council. In fact, I worked as statistician and research coordinator for the Tobacco Research Council (incorporated into the Tobacco Advisory Council in 1977) from 1965 to 1979 . Since 1979 I have worked completely independently as a consultant in statistics and adviser in epidemiology and toxicology for a wide range of companies, including the tobacco industry. Your statement, "The reader may be forgiven for suspecting a possible bias in the book' is understandable but, I assure you, unfounded. would be most happy to discuss the scientific issues concerned with anyone disagreeing with my conclusions.

As regards suspicions of bias, may I be so bold as to refer you to Dr Tony Delamothe's news item on 17 December? ${ }^{2}$ In discussing the issue of passive smoking and lung cancer he stated, "In fact the only people now disputing this claim belong to the tobacco industry." Such a statement seems to me to be unbelievably biased and an unjustified attempt to hamper scientific discussion on an issue on which opinions, in fact, vary widely.

PETER N LEF

Sutton,
Surrey SM2 5DA

Anonymous. What's new in the new editions? Br Med $f$ 1989;298:616. (4 March.

2 Delamothe T. Passive guidelines on smoking. $\mathrm{Br}$. Med 7 1988: 297:1565. (17 December.

\section{Jingoism in pharmaceutical promotion}

SIR, - I feel bound to reply to Dr A Herxheimer's letter criticising British pharmaceutical companies' acknowledgement of their national identity.' I and my colleagues are proud to work for an 85 year old British company employing 11000 people in the United Kingdom, who are working together to discover, develop, manufacture, and market safe and effective medicines of the highest quality.

There has never been any suggestion in our promotion that doctors should prescribe our products because they are British. To respond specifically to Dr Herxheimer, ranitidine (Zantac) is an excellent product in terms of efficacy and safety and for these qualities it is widely prescribed. Nevertheless, it is a British success. It continues to be manufactured here to a standard which again won Glaxo the Queen's award to industry for technological achievement in 1985. Zantac's success also continues to underwrite one of the most ambitious research and development programmes in British industry and the worldwide pharmaceutical industry.

The use of the union jack reflects our pride in being British and for that we make no apology.

Glaxo Laboratories Limited

DAVID JACKSON

Greenford,

Middlesex UB6 $0 \mathrm{H}$

1 Herxheimer A. Jingoism in pharmaceutical promotion. $\mathrm{Br}$ Med $\mathcal{f}$ 1989;298:461. (18 February.)

\section{A mobile surgery for single homeless people}

SIR,-From our work-the primary care for homeless people Bloomsbury project - we would like to endorse two general points made by Dr S S Ramsden and colleagues' and compare and contrast the problems of one of our client groups with those of theirs

We believe that the single homeless in London are a diverse group with varying social and medical problems for which there can be no single solution. We have also found that it is necessary to show a lot of patience before some homeless people can relate to a health care professional.

We hold three surgeries a week at the Simon Community Night Shelter, just north of St Pancras Station. Most clients refer themselves to the shelter, and over $95 \%$ of those given a bed have slept on the streets on the night before admis sion. Between 8 August and 2 December 1988 we saw 92 new clients at this night shelter, the total number of consultations being 277 and the total number of medical problems presented being 366 (table).

Numbers of problems presented at consultation

\begin{tabular}{ll} 
Problem & No \\
\hline Alcoholism & 118 \\
Trauma & 70 \\
Mental illness & 58 (21 chronic schizophrenia) \\
Respiratory conditions & 48 \\
Gastrointestinal conditions & 21 (mainly peptic ulcers and \\
& alcoholic gastritis) \\
Dermatological conditions & 21 (mainly infestations) \\
Other & 30 (main subgroup epilepsy)
\end{tabular}

The problems presented by these clients were similar to those seen by the authors, with trauma being the second commonest problem. Alcoholism and mental illness were, however, far more common among our group. Of the 92 clients, 48 were self reported alcoholics who freely admitted to drinking "as much as possible," and 22 suffered from a mental illness. Many of the medical problems presented by the chronic alcoholics were related to their alcoholism (trauma and alcoholic gastritis), while the large number of consultations for chest infections and infestations was almost certainly related to their homelessness.

$S$ F BENNETT E H GOMM

Primary Care for Homeless People,

London NW 1 lH

1 Ramsden SS, Nyiri P, Bridgewater J, El-Kabir DJ. A mobile surgery for single homeless people in London Br Hed 1989:298:372-4, 11 February

\section{Neurosis induced by home monitoring of blood glucose concentrations}

SIR, - We agree that certain diabetic patients may become obsessive about their home blood glucose measurement, but the assertion that patients, particularly those with obsessive traits, can develop a compulsive neurosis is not supported by the data of Dr S F Beer and colleagues.'

Dr Beer and colleagues fail to show any preexisting compulsive obsessionality in any of the cases they reported. Indeed, after "intensive re-education" all three patients had an $\mathrm{HbA}_{\mathrm{l}}$ concentration above the normal range or at its top end. This argues against an obsessional preoccupation with diabetic control.

Additionally, two patients (cases 1 and 2) had significant alterations in their insulin regimens when home blood glucose monitoring was introduced. Soluble (fast acting) insulins can cause rapid, unpredictable hypoglycaemia, and patients often become extremely confused by rapid variations in their plasma glucose concentration. In desperation they can resort to wild manipulation of their insulin dosages. As alluded to in the article the most important therapeutic manoeuvre at this point is re-education of the patients.

Dr Beer and colleagues conclude that "problems often arise when patients are asked to achieve normal blood glucose concentrations to avoid 